Published in final edited form as:

Am J Physiol Endocrinol Metab. 2011 December ; 301(6): E1236-E1242. doi:10.1152/ajpendo.

00242.2011 .

\title{
Leucine or carbohydrate supplementation reduces AMPK and eEF2 phosphorylation and extends postprandial muscle protein synthesis in rats
}

\author{
Gabriel J. Wilson ${ }^{1}$, Donald K. Layman ${ }^{1}$, Christopher J. Moulton ${ }^{1}$, Layne E. Norton ${ }^{1}$, Tracy \\ G. Anthony ${ }^{2}$, Christopher G. Proud ${ }^{3}$, S. Indu Rupassara ${ }^{4}$, and Peter J. Garlick ${ }^{4}$ \\ ${ }^{1}$ Division of Nutritional Sciences, University of Illinois at Urbana-Champaign, Urbana, Illinois \\ ${ }^{2}$ Department of Biochemistry and Molecular Biology, Indiana University School of Medicine- \\ Evansville, Evansville, Indiana \\ ${ }^{3}$ School of Biological Sciences, University of Southampton, Southampton, United Kingdom \\ ${ }^{4}$ Department of Animal Sciences, University of Illinois, Urbana, Illinois
}

\begin{abstract}
Muscle protein synthesis (MPS) increases after consumption of a protein-containing meal but returns to baseline values within $3 \mathrm{~h}$ despite continued elevations of plasma amino acids and mammalian target of rapamycin (mTORC1) signaling. This study evaluated the potential for supplemental leucine (Leu), carbohydrates (CHO), or both to prolong elevated MPS after a meal. Male Sprague-Dawley rats $(\sim 270 \mathrm{~g})$ trained to consume three meals daily were food deprived for $12 \mathrm{~h}$, and then blood and gastrocnemius muscle were collected 0,90 , or $180 \mathrm{~min}$ after a standard 4 -g test meal (20\% whey protein). At $135 \mathrm{~min}$ postmeal, rats were orally administered $2.63 \mathrm{~g}$ of CHO, $270 \mathrm{mg}$ of Leu, both, or water (sham control). Following test meal consumption, MPS peaked at $90 \mathrm{~min}$ and then returned to basal (time 0 ) rates at $180 \mathrm{~min}$, although ribosomal protein S6 kinase and eIF4E-binding protein-1 phosphorylation remained elevated. In contrast, rats administered Leu and/or CHO supplements at 135 min postmeal maintained peak MPS through $180 \mathrm{~min}$. MPS was inversely associated with the phosphorylation states of translation elongation factor 2, the "cellular energy sensor" adenosine monophosphate-activated protein kinase- $\mathrm{a}$ (AMPKa) and its substrate acetyl-CoA carboxylase, and increases in the ratio of AMP/ATP. We conclude that the incongruity between MPS and mTORC 1 at 180 min reflects a block in translation elongation due to reduced cellular energy. Administering Leu or CHO supplements $\sim 2$ $\mathrm{h}$ after a meal maintains cellular energy status and extends the postprandial duration of MPS.
\end{abstract}

Copyright () 2011 the American Physiological Society

Address for reprint requests and other correspondence: D. K. Layman, Div. of Nutritional Sciences, Univ. of Illinois at UrbanaChampaign, 430 Bevier Hall, 905 S. Goodwin, Urbana, IL 61801 (dlayman@illinois.edu).

DISCLOSURES D. K. Layman is a consultant to Ajinomoto and the ENC. 


\section{Keywords}

eukaryotic elongation factor 2; adenosine $5^{\prime}$-monophosphate-activated protein kinase; translation initiation; translation elongation; branched-chain amino acids; whey protein; mammalian target of rapamycin complex 1

Muscle protein synthesis (MPS) is rapidly stimulated after consumption of a proteincontaining meal and is associated with activation of translation initiation by hormone and nutrient signals (29). Key regulatory points of translation initiation include assembly of the eukaryotic initiation factor-4F (eIF4F) complex and phosphorylation of the 70-kDa ribosomal protein S6 kinase (S6K1). Stimulation of these initiation factors is potentiated by insulin and the essential amino acid (EAA) leucine $(4,5)$. After a meal, plasma concentrations of leucine and insulin trigger the activation of eIF4F and S6K1. Assembly of the eIF4F initiation complex involves phosphorylation of the inhibitory eIF4E-binding protein-1 (4E-BP1), which releases the initiation factor eIF4E and allows it to bind with eIF4G. Binding of eIF4E with eIF4G promotes preparation of the mRNA for binding to the 43S preinitiation complex. The postprandial rise in insulin activates the PI3K-Akt-mTORC1 (phosphoinositide 3-kinase-protein kinase B-mammalian target of rapamycin complex 1) signaling cascade (4), whereas leucine acts downstream of Akt to stimulate mTORC1 through an as-yet unidentified mechanism (12). Apart from the postprandial rise in plasma leucine, MPS does not appear to be limited by amino acids beyond those required to maintain basal levels (31) or by eIF2-mediated formation of the $43 \mathrm{~S}$ preinitiation complex $(6,24)$.

Whereas the initial translation initiation response shortly after a meal $(<2 \mathrm{~h})$ has been well characterized, much less is known about what determines the duration of peak MPS following food intake. Two recent studies $(8,28)$ using precisely timed meals containing intact proteins confirmed that the early postprandial rise of MPS $(<2 \mathrm{~h})$ corresponded to increases in plasma insulin and leucine, as well as assembly of eIF4F and phosphorylation of S6K1 and 4E-BP1, but found that MPS declined by $3 \mathrm{~h}$ despite continued elevations of plasma leucine, mTORC1 signaling, and translation initiation. This discordance between rates of MPS and initiation factor activity suggests that events other than eIF4F complex assembly and S6K1 phosphorylation determine the postprandial MPS response. In both experiments, the postprandial rise and fall of plasma insulin paralleled changes in MPS activity, suggesting that a decline in plasma insulin may limit MPS activity $\sim 3 \mathrm{~h}$ after a meal.

Consistent with the meal-feeding experiments, Bohé et al. (9) infused a complete amino acid mixture into adult volunteers for $6 \mathrm{~h}$. The continuous infusion increased plasma amino acids 1.7-fold above basal levels and stimulated MPS for $\sim 2 \mathrm{~h}$, but MPS subsequently returned to baseline despite the continuous infusion of amino acids. Contrary to these findings, Wilson et al. (36) infused a large dose of leucine to neonatal pigs for $24 \mathrm{~h}$, along with replacement amino acids to maintain basal levels, and found that MPS remained elevated for the entire infusion period. This discrepancy highlights the need for additional research to elucidate factors that determine the duration of the postprandial anabolic period. 
Potential explanations for the discordance between initiation signals and the duration of MPS after a meal include 1) factors or steps within mRNA translation becoming refractory (unresponsive) to external stimuli, 2) reduced availability of amino acids, or 3) reduced signaling from insulin or other important stimuli. The purpose of this study was to determine whether the postprandial period of muscle anabolism can be extended by supplemental doses of leucine, carbohydrates, or both or whether MPS becomes refractory to anabolic stimuli and requires a period of time to reset before it can be stimulated again. A better understanding of the relationship between MPS and the mechanisms leading to active mRNA translation in muscle may have implications for maintenance of lean tissue during weight loss or aging and for treatment of patients suffering trauma or prolonged bed rest as well as for acceleration of muscle development in athletes.

\section{MATERIALS AND METHODS}

Animals

Thirty-four Male Sprague-Dawley rats ( $269 \pm 7 \mathrm{~g}$; Harlan-Teklad, Madison, WI) were housed individually and maintained at $24^{\circ} \mathrm{C}$ with a 12 -h reverse light cycle (light period: 1900-0700). Rats were fed during the dark period and had free access to water. The animal protocol and facilities were reviewed and approved by the Institutional Animal Care and Use Committee of the University of Illinois at Urbana-Champaign.

\section{Meal-training protocol}

Baseline diets provided 20, 50, and 30\% of energy from protein, carbohydrates, and fats, respectively (Table 1). Rats were trained to consume three meals/day consisting of 4-g meals at 0700 and 1300 and a $6-\mathrm{g}$ meal at 1800 . These meals provided $80 \%$ of daily ad libitum intake, which insured that energy intake was equal and that all food was consumed rapidly (within 20 min of introduction; Fig. 1). This food restriction protocol does not alter development of lean tissue but reduces accumulation of body fat (20).

\section{Experimental treatments}

After 7 days of meal training, rats were food deprived for $12 \mathrm{~h}(1900-0700)$ and then euthanized premeal at time 0 (food deprived) or at 90 or $180 \mathrm{~min}$ after the 4-g test meal. Based on our previous study (28), the 90-min time point represented peak MPS activity, whereas the 180-min time point reflected a period of time when mTORC1 signaling and initiation factor activity was elevated, but MPS returned to baseline values. At $135 \mathrm{~min}$ after the test meal, rats were administered a 5-ml oral gavage of carbohydrates (CHO), leucine (Leu), CHO + Leu (LC), or a sham (water) control (Fig. 1).

The CHO supplement contained $2.63 \mathrm{~g}$ of $\mathrm{CHO}(1.315 \mathrm{~g}$ of glucose $+1.315 \mathrm{~g}$ of sucrose $)$ in distilled water, which was slightly greater than the carbohydrate content of the $4 \mathrm{~g}$ meal $(\sim 2.2 \mathrm{~g})$. The Leu supplement contained $270 \mathrm{mg}$ of Leu in distilled water, which was equivalent to the daily amount of Leu consumed by rats of this age and strain, with free access to the AIN-93 powdered diet (Harlan-Teklad) (19) and nearly three times the leucine content of the 4-g meal ( 100 mg). The LC supplement contained $2.36 \mathrm{~g}$ of CHO (1.18 g of glucose $+1.18 \mathrm{~g}$ of sucrose) and $270 \mathrm{mg}$ of Leu in distilled water, which was isocaloric with 
the $\mathrm{CHO}$ gavage and isonitrogenous with the Leu gavage. The $\mathrm{CHO}$ and $\mathrm{LC}$ supplements supplied $\sim 15 \%$ of daily energy intake for this age and strain of rat (19). The amounts and timing of the supplements were based on our previous research that produced maximal Leuand insulin-induced stimulations of translation initiation and MPS 45 min after oral gavage $(2,3,6,12)$.

\section{Administration of metabolic tracer and sample collection}

MPS was measured in skeletal muscle using the flooding dose method (18). A 100\% enriched $\mathrm{L}_{-}\left[{ }^{2} \mathrm{H}_{5}\right]$ phenylalanine solution ( $150 \mathrm{mmol} / \mathrm{l}$; Cambridge Isotopes, Andover, MA) was administered at $150 \mathrm{mmol} / 100 \mathrm{~g}$ body wt and injected via tail vein $(1 \mathrm{ml} / 100 \mathrm{~g}$ body wt). After $10 \mathrm{~min}$, animals were euthanized by decapitation, blood was collected in precoated EDTA tubes, and hindlimbs were quickly removed and immersed in an ice-water mixture. Gastrocnemius muscles were removed from cooled hindlimbs, frozen in liquid $\mathrm{N}_{2}$, and stored at $-80^{\circ} \mathrm{C}$.

\section{Determination of MPS}

Frozen muscle tissue was powdered in liquid nitrogen, and protein was precipitated with cold $\left(4^{\circ} \mathrm{C}\right)$ perchloric acid $(30 \mathrm{~g} / 1,1 \mathrm{ml} / 50 \mathrm{mg}$ muscle tissue). The resulting supernatant and protein pellet were prepared for MPS analysis, as described previously $(16,26)$. The enrichment of $\mathrm{L}_{\mathrm{L}}\left[{ }^{2} \mathrm{H}_{5}\right]$ phenylalanine in the muscle hydrolysate was measured by GC-MS using a 6890N GC and a 5973N mass detector (Agilent Technologies, Santa Clara, CA). Samples were analyzed under electron impact ionization in splitless mode, and the mass-tocharge ratio of phenylethylamine ions at $106(m+2)$ and $109(m+5)$ were monitored for enrichment.

The muscle supernatant was used to determine intracellular free phenylalanine enrichment. Free amino acids were purified by ion exchange resin solid-phase extraction using the EZ Fast amino acid analysis sample testing kit (Phenomenex, Torrance, CA), and $\mathrm{L}^{-}$ $\left[{ }^{2} \mathrm{H}_{5}\right]$ phenylalanine enrichment was determined using a propyl chloroformate derivative with GC-MS by monitoring the ions at mass-to-charge ratios of $206(m)$ and $211(m+5)$ (27).

MPS was assessed from the rate of incorporation of ${ }_{\mathrm{L}-}\left[{ }^{2} \mathrm{H}_{5}\right]$ phenylalanine into total mixedmuscle protein, as described previously (26). The time from injection of the tracer until tissue cooling was recorded as the actual time for $\mathrm{L}_{-}\left[{ }^{2} \mathrm{H}_{5}\right]$ phenylalanine incorporation. MPS, defined as the percentage of tissue protein renewed each day, was calculated according to the formula MPS $=\left(\mathrm{E}_{\mathrm{b}} \times 100\right) /\left(\mathrm{E}_{\mathrm{a}} \times t\right)$, where $t$ is the time interval between injection and cooling of sampled tissue expressed in days and $\mathrm{E}_{\mathrm{b}}$ and $\mathrm{E}_{\mathrm{a}}$ are the enrichments of $\left[{ }^{2} \mathrm{H}_{5}\right] \mathrm{Phe}$ in hydrolyzed tissue protein and muscle free amino acids, respectively.

\section{Plasma measurements}

Plasma was obtained from trunk blood by centrifugation at $1,800 \mathrm{~g}$ for $10 \mathrm{~min}$ at $4^{\circ} \mathrm{C}$. Plasma insulin concentrations were analyzed using a commercial RIA kit for rat insulin (Millipore, Billerica, MA). Plasma amino acid concentrations were determined by HPLC using a Waters (Milford, MA) 2475 fluorescence detector (30). 


\section{Western blot analysis}

Muscle supernatants were subjected to protein immunoblot analysis, as described previously (12). Rabbit polyclonal antibodies were used for total and phosphorylated (phospho)-S6K1 $\left(\mathrm{Thr}^{389}\right)$, total and phospho-4E-BP1 $\left(\mathrm{Thr}^{37 / 46}\right)$, total and phospho-eukaryotic elongation factor $2\left(\mathrm{eEF} 2\right.$; $\left.\mathrm{Thr}^{56}\right)$, total and phospho-AMPKa $\left(\mathrm{Thr}^{172}\right)$, total and phospho-ACC (acetylCoA carboxylase; $\left.\mathrm{Ser}^{79}\right)$, total and phospho-Akt $\left(\mathrm{Ser}^{473}\right)$, and total and phospho-eIF2a $\left(\mathrm{Ser}^{51}\right.$; eIF2a) as well as total and phospho-eIF2B $\varepsilon$ (phospho-Ser ${ }^{535}$ ) (Invitrogen, Camarillo, CA). All primary antibodies used were purchased from Cell Signaling Technology (Boston, MA) unless stated otherwise. Anti-rabbit IgG, horseradish peroxidase-linked secondary antibody was also purchased from Cell Signaling Technology.

\section{Nucleotide analysis}

Adenosine 5'-monophosphate (AMP) and adenosine $5^{\prime}$-triphosphate (ATP) were determined by HPLC analysis, as described in a technical note $\mathrm{CN}-039$ by Phenomenex (Torrance, CA). Briefly, frozen gastrocnemius muscle was ground under liquid nitrogen, and $50 \mathrm{mg}$ of sample was combined with $1 \mathrm{ml}$ of $\mathrm{MeOH}$ in water (25:75) and vortexed. This sample was centrifuged at $10,000 \mathrm{rpm}$ at $4{ }^{\circ} \mathrm{C}$ for $5 \mathrm{~min}$, and the supernatant was extracted. The supernatant was dried and then reconstituted in phosphate-buffered saline. The sample was then passed through a Strata X-AW 33u Polymeric Weak Anion Solid Phase Extraction Sorbent (Phenomenex, Torrance, CA). Ten-microliter aliquots of the final muscle extract were injected onto the HPLC using a Phenomenex Gemini 5u C18 110A Column $150 \times 4.6$ $\mathrm{mm}$ with temperature set at $25^{\circ} \mathrm{C}$. A single mobile phase was used at a flow rate of $1 \mathrm{ml} / \mathrm{min}$ with $25 \%$ acetonitrile- $10 \mathrm{mM} \mathrm{KH}_{2} \mathrm{PO}_{4}, \mathrm{pH} 7.0$ (pH was adjusted with potassium hydroxide/5 $\mathrm{mM}$ tetrabutylammonium chloride). Nucleotide peaks were measured by UV detection at a wavelength of $260 \mathrm{~nm}$. Peaks were identified by comparison with external standards (Sigma-Aldrich, St. Louis, MO).

\section{Statistical analysis}

All data were analyzed by SPSS 15.0 software package for Windows (Chicago, IL). A oneway ANOVA was performed with the postprandial times and oral gavage treatments as the independent variables. When a significant overall effect was detected, differences among individual means were assessed using a least significant difference post hoc test. For plasma amino acids, a oneway ANOVA was performed for meal (0, 90, and $180 \mathrm{~min})$ and supplement effects (sham, CHO, Leu, and LC at $180 \mathrm{~min}$ ). Correlations were determined by linear regression (Pearson correlation). The level of significance was set at $P<0.05$ for all statistical tests. Values are presented as means \pm SE.

\section{RESULTS}

This experiment evaluated the potential for supplemental Leu or $\mathrm{CHO}$ to extend the peak MPS response after a meal. Consistent with our previous research (28), we found that MPS increased at $90 \mathrm{~min}$ after a 4-g test meal but then returned to food-deprived values at 180 min (sham). Supplementation with Leu, CHO, or LC 135 min after the test meal significantly increased MPS at $180 \mathrm{~min}$ above sham rats and equal to meal-fed rats at $90 \mathrm{~min}$ (Fig. 2). 
To understand the mechanisms explaining these findings, we first examined changes in plasma amino acid concentrations. As expected, plasma leucine and EAAs increased $90 \mathrm{~min}$ after the meal and remained elevated at $180 \mathrm{~min}$ (Table 2).

Administering the Leu supplements at 135 min elevated plasma leucine at $180 \mathrm{~min}$; however, Leu and LC also depressed plasma isoleucine and valine below sham values (Fig. 3). Likewise, the $\mathrm{CHO}$ gavage lowered plasma branched-chain amino acids (BCAA; Leu, isoleucine, and valine) below sham levels. The supplements had no effect on levels of other measured plasma EAAs, including methionine, threonine, and lysine, relative to Sham control (Fig. 3).

Phosphorylation of S6K1 $\left(\mathrm{Thr}^{389}\right)$ was measured as a marker of mTORC1 signaling. Consistent with previous reports $(8,28)$, relative phosphorylation of S6K1 $\left(\mathrm{Thr}^{389}\right)$ in muscle increased at $90 \mathrm{~min}(P<0.05)$ and remain elevated at $180 \mathrm{~min}$ (sham control) compared with food-deprived rats (time $0, P<0.05$; Fig. 4). Likewise, supplemental treatments maintained S6K1 activation at $180 \mathrm{~min}$. From 0 to $90 \mathrm{~min}$, there was a significant correlation between S6K1 phosphorylation and MPS $(r=0.843, P<0.05)$. However, from 90 to 180 min after the meal, no statistical correlation was present $(r=0.163, P>0.05)$. Similar results were seen for phospho-4E-BP1 (Thr ${ }^{37 / 46}$; Fig. 4).

To evaluate other steps in translation initiation, we examined phosphorylation of regulatory sites in eIF2a $\left(\mathrm{Ser}^{51}\right)$ and eIF2B $\varepsilon\left(\mathrm{Ser}^{535}\right)$ as markers of eIF2 activation. No changes in phosphorylation of either of these proteins were found (data not shown).

Consistent with earlier publications $(8,28)$, plasma insulin rose at 90 min postmeal and returned to food-deprived (time 0 ) values at $180 \mathrm{~min}$ (sham) (Fig. 5). The $\mathrm{CHO}$ and LC supplements maintained elevated insulin at $180 \mathrm{~min}$, whereas the Leu supplement was not different from the sham group at $180 \mathrm{~min}$. Phosphorylation of Akt $\left(\mathrm{Ser}^{473}\right)$ was measured as an indicator of insulin signaling, but no differences in Akt activation were detected among the groups at $180 \mathrm{~min}$ (data not shown).

Since the decline in MPS at 180 min postmeal (sham) was not related to changes in EAAs, plasma insulin, or phosphorylation of S6K1, eIF2a, or eIF2B $\varepsilon$, we then examined phosphorylation of eEF2 $\left(\mathrm{Thr}^{56}\right)$, an essential regulator of translation elongation. After the meal, eEF2 phosphorylation decreased from 0 to $90 \mathrm{~min}$, reflecting activation of elongation for MPS, but returned to food-deprived (time 0 ) values at $180 \mathrm{~min}$ postmeal (sham control), consistent with inhibition of elongation (Fig. 6) and the decline in MPS. All three supplements (Leu, CHO, and LC) reduced eEF2 phosphorylation at 180 min relative to sham control. Across all treatment groups, there was an inverse association between phospho-eEF2 and MPS $(r=-0.500, P<0.05)$.

Phosphorylation of AMPKa $\left(\mathrm{Thr}^{172}\right)$ and its substrate ACC $\left(\mathrm{Ser}^{79}\right)$ and the nucleotide ratio of AMP/ATP were measured as indicators of cellular energy status (Fig. 7). In meal-fed rats, phosphorylation of muscle AMPKa and ACC (21) declined at 90 min compared with fooddeprived rats, reflecting increased energy availability, but increased at $180 \mathrm{~min}$, reflecting decreased energy availability. All three of the supplemental treatments maintained reduced phospho-AMPKa and ACC at levels similar to the 90-min postmeal values. Similarly to 
changes in phospho-AMPKa and ACC, the ratio of AMP/ATP [allosteric regulator of AMPK (22) and a direct measurement of cellular energy status] declined at 90-min postmeal but increased above food-deprived values at $180 \mathrm{~min}$. Each of the supplements served to maintain a reduced ratio of AMP/ATP at $180 \mathrm{~min}$, consistent with the behaviors of AMPKa and ACC.

\section{DISCUSSION}

This study demonstrates that Leu or $\mathrm{CHO}$ supplements provided $\sim 2 \mathrm{~h}$ after consumption of a complete meal can extend the postprandial anabolic period of MPS (Fig. 2). Furthermore, the findings of this study suggest that the incongruity between MPS and mTORC1 signaling 180 min after a meal is associated with activation of AMPK (Fig. 7) and reduced translation elongation activity (Fig. 6). These data suggest that temporal changes in skeletal muscle energy state following meal feeding influence the period of muscle anabolism. Furthermore, the energy status of muscle can be enhanced by postmeal nutrition supplements to extend the period of muscle anabolism.

Translation initiation is a critical regulatory step for stimulating the rise in MPS after a meal and is activated by nutrient signals derived from changes in plasma insulin and Leu and propagated through the PI3K-Akt-mTORC1 signaling cascade (4). Triggering of initiation and maximum MPS activity occurs within 30 to 60 min following administration of free Leu (6) and 60 to $90 \mathrm{~min}$ following ingestion of intact proteins $(8,28)$. Two recent studies $(8,28)$ using precisely timed meals containing intact proteins confirmed that the early postprandial rise of MPS ( $<2 \mathrm{~h}$ ) corresponded to increases in plasma insulin and Leu, as well as phosphorylation of S6K1 and 4E-BP1 and assembly of the eIF4F initiation complex, but found that MPS declined after $3 \mathrm{~h}$ despite continued elevations of plasma Leu, mTORC1 signaling, and translation initiation. The present study is consistent with these reports, finding a postprandial rise in plasma Leu and significant correlation between phospho-S6K1 and MPS ( $r=0.843, P<0.05$ ) from 0 to $90 \mathrm{~min}$ after the test meal (Fig. 4). However, from 90 to 180 min postmeal, the correlation between phospho-S6K1 and MPS disappears ( $r=$ $0.163, P>0.05$; Fig. 4). Likewise, similar results were found for phospho-4E-BP1 (Fig. 4). Furthermore, no changes in the phosphorylation states of eIF2a or eIF2B $\varepsilon$ were found, suggesting that eIF2 is unlikely to be a regulatory factor for postprandial changes in MPS. Collectively, these findings are consistent with the hypothesis that translation initiation signaling via mTORC1 facilitates the initial rise in MPS after a meal; however, factors in addition to translation initiation are required to sustain peak MPS 180 min after a meal (8, 28).

Potential explanations for the discordance between initiation signals and the postprandial duration of MPS include 1) factors or steps within mRNA translation becoming refractory (unresponsive) to external stimuli, 2) reduced availability of amino acids, or 3) reduced signaling from insulin or other important signals. In the present study, all three nutrient supplements were able to extend the duration of peak MPS, demonstrating that mRNA translation is not refractory to anabolic stimuli but rather limited by one or more regulatory factors. Therefore, we sought to determine what factors limited the postprandial duration of MPS and why either Leu or CHO supplements overcame these limitation(s). 
We found that plasma essential amino acids remained elevated at 180 min after the meal (sham control) relative to the 90-min time point and that Leu or $\mathrm{CHO}$ treatments were sufficient to extend MPS without providing additional amino acids (Table 2), establishing that availability of essential amino acids was not a primary limitation during the decline in MPS.

Likewise, insulin does not appear to be a critical factor in extending MPS (Fig. 5). As expected, the $\mathrm{CHO}$ treatments ( $\mathrm{CHO}$ and LC) increased plasma insulin concentration at 180 min compared with the sham control; however, the Leu treatment, which prolonged the duration of MPS at $180 \mathrm{~min}$, did not maintain elevated insulin concentration at $180 \mathrm{~min}$. There were no differences between groups in phosphorylation of the insulin-signaling target Akt at 180 min (data not shown). However, we have shown previously that peak insulin and Akt responses occur $30 \mathrm{~min}$ after a complete meal (14) and <20 min after administration of these supplements (4). Therefore, the time point measurements used in this study most likely missed peak insulin and Akt responses. Thus, the influence of insulin signaling on the duration of MPS remains unresolved.

Another possible determinant of the postmeal reduction in MPS is a decrease in translation elongation. In this experiment, phosphorylation of eEF2 $\left(\mathrm{Thr}^{56}\right)$ was used as an indicator for translation elongation activity. We found increased phosphorylation of eEF2 in the sham control, indicating inhibition of eEF2 at $180 \mathrm{~min}$ after the test meal (Fig. 6). Conversely, phosphorylation of eEF2 was reduced by each of the supplements at $180 \mathrm{~min}$, consistent with sustained elevation of MPS after the meal.

Brown et al. (11) and Horman et al. (23) have shown that inhibition of eEF2 and protein synthesis in response to mild energy deficits is associated with activation of AMPK, which stimulates the regulatory kinase eEF2 kinase to subsequently phosphorylate (inhibit) eEF2. The ability of AMPK to respond to changes in AMP/ATP, with AMP stimulating AMPK and ATP inhibiting it, allows this kinase to be an effective cellular energy sensor (22). We measured AMPKa phosphorylation, the ratio of AMP/ATP, and phosphorylation of ACC to determine whether energy status of muscle could be a limiting factor for MPS $180 \mathrm{~min}$ after a meal (Fig. 7). Consistent with the energy hypothesis, each of the biomarkers for cellular energy status reflected energy stress in the cell and produced a pattern of change nearly identical with that observed for eEF2 (Fig. 6). Furthermore, there was a significant inverse correlation across treatments between MPS and AMPKa phosphorylation $(r=-0.581, P<$ 0.05). Collectively, these results suggest that energy is a likely determinant of the duration of postprandial MPS and that eEF2 is the regulatory step responding to energy status.

When considering the upstream regulators of translation initiation and elongation, there appears to be a paradox in these signals. Indeed, AMPK and mTORC1 are both regulators of translation initiation and elongation but act in opposing ways, with AMPK inhibiting translation initiation (7) and elongation (10) and mTORC1 stimulating these processes (33). The findings that both mTORC1 $(8,28)$ and AMPK (Fig. 7$)$ are activated during the postprandial decline in MPS suggests that AMPK and energy become the dominant signals. Furthermore, the finding that eEF2, a key regulator of translation elongation, is inhibited, 
coinciding with downregulation of MPS, indicates that the AMPK inhibitory effect on eEF2 overrides the stimulatory effects of mTORC1.

Support for this hierarchal form of regulation is provided from research by Browne and colleagues (10, 11), Horman et al. (23), McLeod and Proud (25), and Smith et al. (32). In a variety of cell lines $(10,23,25,32)$ these authors have shown that, under mild energy deficits, AMPK activation results in strong and rapid inhibition of eEF2 and translation elongation, with no corresponding changes in phosphorylation of proteins involved in the initiation stages of mRNA translation, including eIF2, p70 S6K1, 4E-BP1, and assembly of the eIF4F initiation complex. Contrary to these findings, Dennis et al. (13) demonstrated inhibition of mTORC1 signaling using higher concentrations of the AMPK agonist 2deoxyglucose [10-fold greater than Browne and colleagues (10, 11), Horman et al. (23), McLeod and Proud (25), and Smith et al. (32)]. Likewise, Williamson et al. (35) reported inhibition of mTORC1 signaling by AMPK using higher levels of 5-aminoimidazole-4carboxamide-1- $\beta$-D-ribonucleoside [double the amount of Browne and colleagues $(10,11)$, Horman et al. (23), McLeod and Proud (25), and Smith et al. (32)]. Overall, the current study and the published reports by Browne and colleagues $(10,11)$, Horman et al. (23), McLeod and Proud (25), and Smith et al. (32) suggest that the physiological regulation of cellular energy status by AMPK exerts a dominant effect over the anabolic stimulation of MPS by mTORC1.

Considering that protein turnover is a metabolically costly process, accounting for approximately one-quarter of resting energy expenditure (34), it is logical that a cell would suppress protein synthesis activity during an energy deficit to preserve critical functions. Furthermore, when considering that translation elongation accounts for the majority (>99\%) of the energy used for polypeptide assembly $(10,11,29)$, it appears logical that the cell would regulate translation elongation to protect energy status.

The finding that the large Leu supplement was able to decrease AMPKa phosphorylation is consistent with the work from Du et al. (15), who showed that Leu treatment in $\mathrm{C}_{2} \mathrm{C}_{12}$ myoblast cells resulted in a $36 \%$ decrease in the AMP/ATP ratio, a $28 \%$ reduction in phospho-AMPKa, and a $43 \%$ reduction in AMPK activity. Leu can provide energy (ATP) to muscle by conversion to ketoisocaproate (KIC) and its subsequent oxidation via the TCA cycle. Increased KIC levels in skeletal muscle have also been shown to increase oxidation of all three BCAAs (Leu, isoleucine, and valine) by allosteric activation of branched-chain aketo-acid dehydrogenase $(1,17)$. In support of the hypothesis that Leu increased BCAA oxidation, the Leu-containing supplements in the present experiment reduced isoleucine and valine concentrations by $50-150 \%$, whereas other plasma EAAs remained unchanged relative to sham control (Fig. 3).

In summary, intake of a Leu or CHO supplements $\sim 2 \mathrm{~h}$ after consumption of a complete meal can extend the duration of the postprandial rise in MPS. Furthermore, the incongruity between MPS and mTORC1 signaling at $180 \mathrm{~min}$ after the meal does not reflect a refractory period or decreased sensitivity to anabolic stimuli but rather an increase in AMPK activity and a decrease in translation elongation activity. Improved understanding of factors that regulate the duration of MPS may have implications for maintenance of lean tissue during 
weight loss or aging for treatment of patients suffering trauma or prolonged bed rest as well as for acceleration of muscle development in athletes. As such, the roles of eEF2 and AMPK in regulation of postprandial MPS warrant further investigation.

\section{Acknowledgments}

GRANTS This work was supported by grants from Ajinomoto and the Egg Nutrition Center (ENC).

\section{REFERENCES}

1. Aftring RP, Block KP, Buse MG. Leucine and isoleucine activate skeletal muscle branched-chain aketo acid dehydrogenase in vivo. Am J Physiol Endocrinol Metab. 1986; 250:E599-E604.

2. Anthony JC, Anthony TG, Kimball SR, Vary TC, Jefferson LS. Orally administered leucine stimulates protein synthesis in skeletal muscle of postabsorptive rats in association with increased eIF4F formation. J Nutr. 2000; 130:139-145. [PubMed: 10720160]

3. Anthony JC, Anthony TG, Layman DK. Leucine supplementation enhances skeletal muscle recovery in rats following exercise. J Nutr. 1999; 129:1102-1106. [PubMed: 10356072]

4. Anthony JC, Lang CH, Crozier SJ, Anthony TG, MacLean DA, Kimball SR, Jefferson LS. Contribution of insulin to the translational control of protein synthesis in skeletal muscle by leucine. Am J Physiol Endocrinol Metab. 2002; 282:E1092-E1101. [PubMed: 11934675]

5. Anthony JC, Yoshizawa F, Anthony TG, Vary TC, Jefferson LS, Kimball SR. Leucine stimulates translation initiation in skeletal muscle of postabsorptive rats via a rapamycin-sensitive pathway. J Nutr. 2000; 130:2413-2419. [PubMed: 11015466]

6. Anthony TG, Anthony JC, Yoshizawa F, Kimball SR, Jefferson LS. Oral administration of leucine stimulates ribosomal protein mRNA translation but not global rates of protein synthesis in the liver of rats. J Nutr. 2001; 131:1171-1176. [PubMed: 11285321]

7. Atherton PJ, Babraj J, Smith K, Singh J, Rennie MJ, Wackerhage H. Selective activation of AMPKPGC-1alpha or PKB-TSC2-mTOR signaling can explain specific adaptive responses to endurance or resistance training-like electrical muscle stimulation. FASEB J. 2005; 19:786-788. [PubMed: 15716393]

8. Atherton PJ, Etheridge T, Watt PW, Wilkinson D, Selby A, Rankin D, Smith K, Rennie MJ. Muscle full effect after oral protein: time-dependent concordance and discordance between human muscle protein synthesis and mTORC1 signaling. Am J Clin Nutr. 2010; 92:1080-1088. [PubMed: 20844073]

9. Bohé J, Low JF, Wolfe RR, Rennie MJ. Latency and duration of stimulation of human muscle protein synthesis during continuous infusion of amino acids. J Physiol. 2001; 532:575-579. [PubMed: 11306673]

10. Browne GJ, Finn SG, Proud CG. Stimulation of the AMP-activated protein kinase leads to activation of eukaryotic elongation factor 2 kinase and to its phosphorylation at a novel site, serine 398. J Biol Chem. 2004; 279:12220-12231. [PubMed: 14709557]

11. Browne GJ, Proud CG. Regulation of peptide-chain elongation in mammalian cells. Eur $\mathbf{J}$ Biochem. 2002; 269:5360-5368. [PubMed: 12423334]

12. Crozier SJ, Kimball SR, Emmert SW, Anthony JC, Jefferson LS. Oral leucine administration stimulates protein synthesis in rat skeletal muscle. J Nutr. 2005; 135:376-382. [PubMed: 15735066]

13. Dennis PB, Jaeschke A, Saitoh M, Fowler B, Kozma SC, Thomas G. Mammalian TOR: a homeostatic ATP sensor. Science. 2001; 294:1102-1105. [PubMed: 11691993]

14. Devkota S, Layman DK. Increased ratio of dietary carbohydrate to protein shifts the focus of metabolic signaling from skeletal muscle to adipose. Nutr Metab (Lond). 2011; 8:13. [PubMed: 21375752]

15. Du M, Shen QW, Zhu MJ, Ford SP. Leucine stimulates mammalian target of rapamycin signaling in $\mathrm{C} 2 \mathrm{C} 12$ myoblasts in part through inhibition of adenosine monophosphate-activated protein kinase. J Anim Sci. 2007; 85:919-927. [PubMed: 17178807] 
16. Essen P, McNurlan MA, Gamrin L, Hunter K, Calder G, Garlick PJ, Wernerman J. Tissue protein synthesis rates in critically ill patients. Crit Care Med. 1998; 26:92-100. [PubMed: 9428549]

17. Fujii H, Shimomura Y, Tokuyama K, Suzuki M. Modulation of branched-chain 2-oxo acid dehydrogenase complex activity in rat skeletal muscle by endurance training. Biochim Biophys Acta. 1994; 1199:130-136. [PubMed: 8123661]

18. Garlick PJ, McNurlan MA, Preedy VR. A rapid and convenient technique for measuring the rate of protein synthesis in tissues by injection of [3H]phenylalanine. Biochem J. 1980; 192:719-723. [PubMed: 6786283]

19. Gautsch TA, Anthony JC, Kimball SR, Paul GL, Layman DK, Jefferson LS. Availability of eIF4E regulates skeletal muscle protein synthesis during recovery from exercise. Am J Physiol Cell Physiol. 1998; 274:C406-C414.

20. Glore SR, Layman DK. Cellular growth of skeletal muscle in weanling rats during dietary restrictions. Growth. 1983; 47:403-410. [PubMed: 6199262]

21. Ha J, Daniel S, Broyles SS, Kim KH. Critical phosphorylation sites for acetyl-CoA carboxylase activity. J Biol Chem. 1994; 269:22162-22168. [PubMed: 7915280]

22. Hardie DG. Minireview: the AMP-activated protein kinase cascade: the key sensor of cellular energy status. Endocrinology. 2003; 144:5179-5183. [PubMed: 12960015]

23. Horman S, Browne G, Krause U, Patel J, Vertommen D, Bertrand L, Lavoinne A, Hue L, Proud C, Rider M. Activation of AMP-activated protein kinase leads to the phosphorylation of elongation factor 2 and an inhibition of protein synthesis. Curr Biol. 2002; 12:1419-1423. [PubMed: 12194824]

24. Kobayashi H, Borsheim E, Anthony TG, Traber DL, Badalamenti J, Kimball SR, Jefferson LS, Wolfe RR. Reduced amino acid availability inhibits muscle protein synthesis and decreases activity of initiation factor eIF2B. Am J Physiol Endocrinol Metab. 2003; 284:E488-E498. [PubMed: 12556349]

25. McLeod LE, Proud CG. ATP depletion increases phosphorylation of elongation factor eEF2 in adult cardiomyocytes independently of inhibition of mTOR signalling. FEBS Lett. 2002; 531:448452. [PubMed: 12435591]

26. McNurlan MA, Essén P, Thorell A, Calder AG, Anderson SE, Ljungqvist O, Sandgren A, Grant I, Tjäder I, Ballmer PE, Wernerman J, Garlick PJ. Response of protein synthesis in human skeletal muscle to insulin: an investigation with $1-\left[{ }^{2} \mathrm{H}_{5}\right]$ phenylalanine. Am J Physiol Endocrinol Metab. 1994; 267:E102-E108.

27. Mohabbat T, Drew B. Simultaneous determination of 33 amino acids and dipeptides in spent cell culture media by gas chromatography-flame ionization detection following liquid and solid phase extraction. J Chromatogr B Analyt Technol Biomed Life Sci. 2008; 862:86-92.

28. Norton LE, Layman DK, Bunpo P, Anthony TG, Brana DV, Garlick PJ. The leucine content of a complete meal directs peak activation but not duration of skeletal muscle protein synthesis and mammalian target of rapamycin signaling in rats. J Nutr. 2009; 139:1103-1109. [PubMed: 19403715]

29. Proud CG. Signalling to translation: how signal transduction pathways control the protein synthetic machinery. Biochem J. 2007; 403:217-234. [PubMed: 17376031]

30. Reverter M, Lundh T, Lindberg JE. Determination of free amino acids in pig plasma by precolumn derivatization with 6-N-aminoquinolyl-N-hydroxysuccinimidyl carbamate and high-performance liquid chromatography. J Chromatogr B Biomed Sci Appl. 1997; 696:1-8. [PubMed: 9300902]

31. Rieu I, Balage M, Sornet C, Giraudet C, Pujos E, Grizard J, Mosoni L, Dardevet D. Leucine supplementation improves muscle protein synthesis in elderly men independently of hyperaminoacidaemia. J Physiol. 2006; 575:305-315. [PubMed: 16777941]

32. Smith EM, Finn SG, Tee AR, Browne GJ, Proud CG. The tuberous sclerosis protein TSC2 is not required for the regulation of the mammalian target of rapamycin by amino acids and certain cellular stresses. J Biol Chem. 2005; 280:18717-18727. [PubMed: 15772076]

33. Wang X, Li W, Williams M, Terada N, Alessi DR, Proud CG. Regulation of elongation factor 2 kinase by p90(RSK1) and p70 S6 kinase. EMBO J. 2001; 20:4370-4379. [PubMed: 11500364]

34. Welle S, Nair KS. Relationship of resting metabolic rate to body composition and protein turnover. Am J Physiol Endocrinol Metab. 1990; 258:E990-E998. 
35. Williamson DL, Bolster DR, Kimball SR, Jefferson LS. Time course changes in signaling pathways and protein synthesis in $\mathrm{C}_{2} \mathrm{C}_{12}$ myotubes following AMPK activation by AICAR. Am $\mathrm{J}$ Physiol Endocrinol Metab. 2006; 291:E80-E89. [PubMed: 16760336]

36. Wilson FA, Suryawan A, Gazzaneo MC, Orellana RA, Nguyen HV, Davis TA. Stimulation of muscle protein synthesis by prolonged parenteral infusion of leucine is dependent on amino acid availability in neonatal pigs. J Nutr. 2009; 140:264-270. [PubMed: 20032489] 


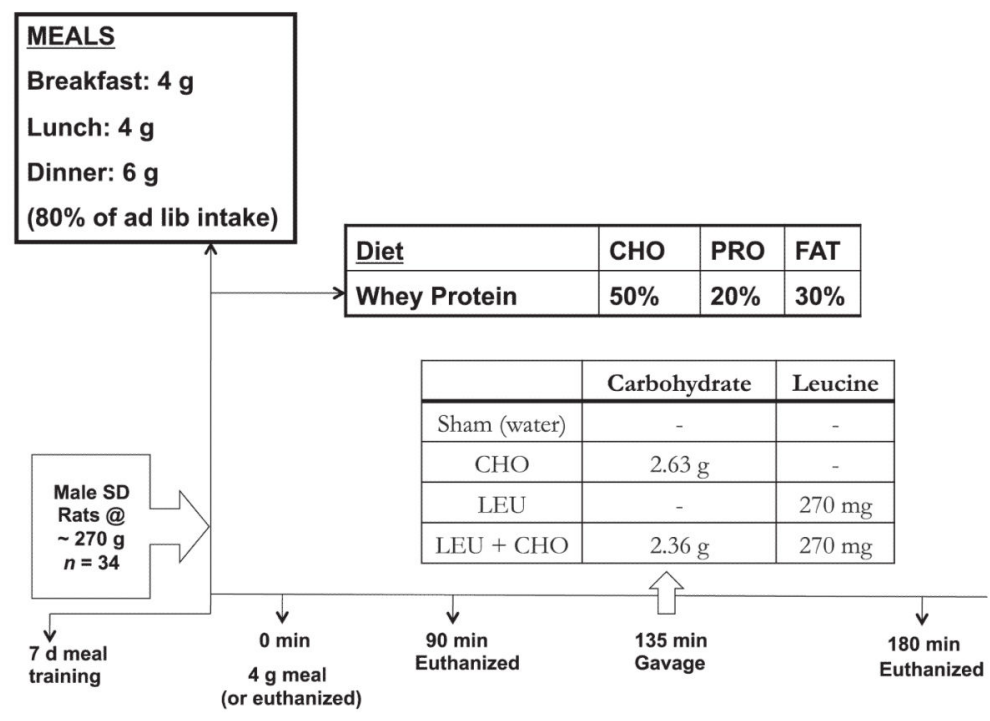

Fig. 1.

Experimental design and timeline. Treatment groups were intubated at $135 \mathrm{~min}$ after the meal with water (sham), carbohydrates (CHO), leucine (Leu), or combination of $\mathrm{CHO}+\mathrm{Leu}$ (LC). 


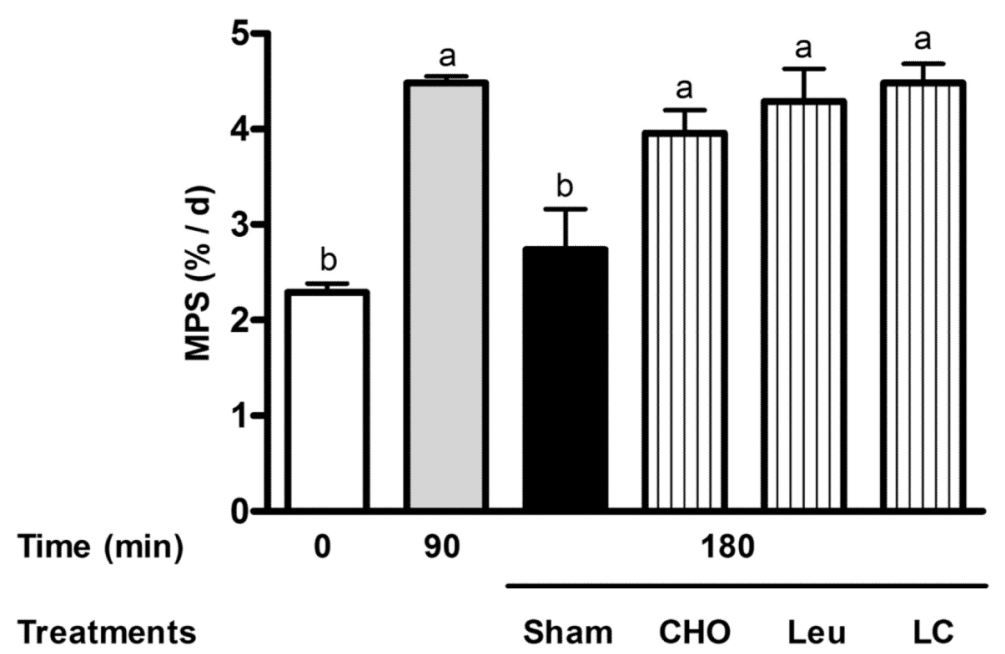

Fig. 2.

Postprandial changes for muscle protein synthesis (MPS). Treatment groups were intubated at 135 min after the meal with water (sham), CHO, Leu, or LC. Data are means \pm SE; $n=4-$ 6. Means without a common letter differ $(P<0.05)$. 


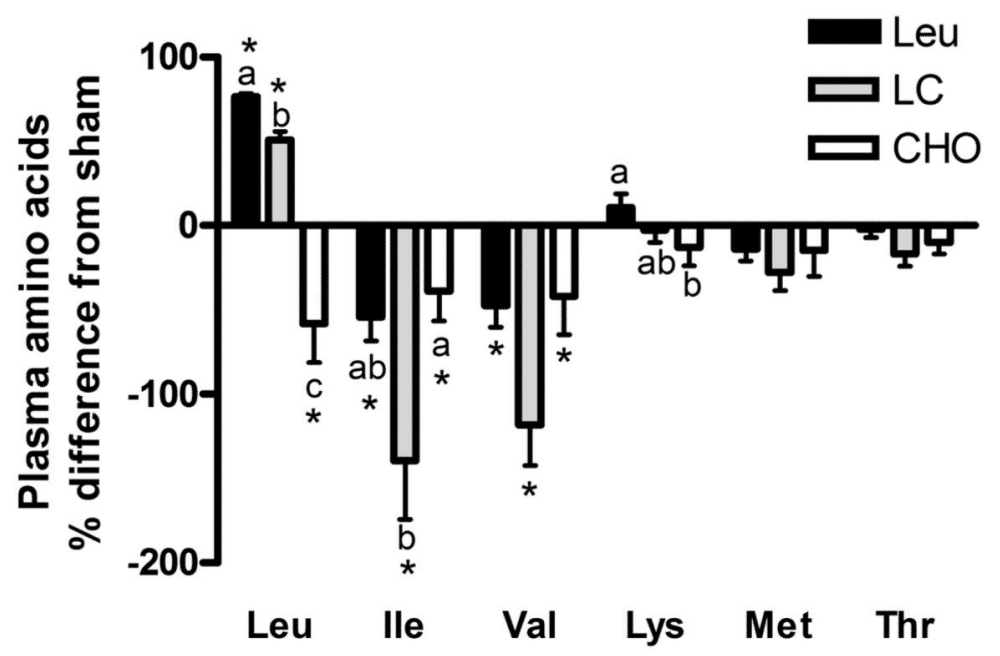

Fig. 3.

$\%$ Difference of selected plasma amino acid concentrations from control (sham treatment) for each supplement. Data are means $\pm \mathrm{SE} ; n=6$. Treatment groups were intubated at 135 min after the meal with water (sham), CHO, Leu, or LC, with measurements taken 180 min after the meal. Means without a common letter differ $(P<0.05)$. *Amino acid differs from sham $(P<0.05)$. Ile, isoleucine; Val, valine; Lys, lysine; Met, methionine; Thr, threonine. 


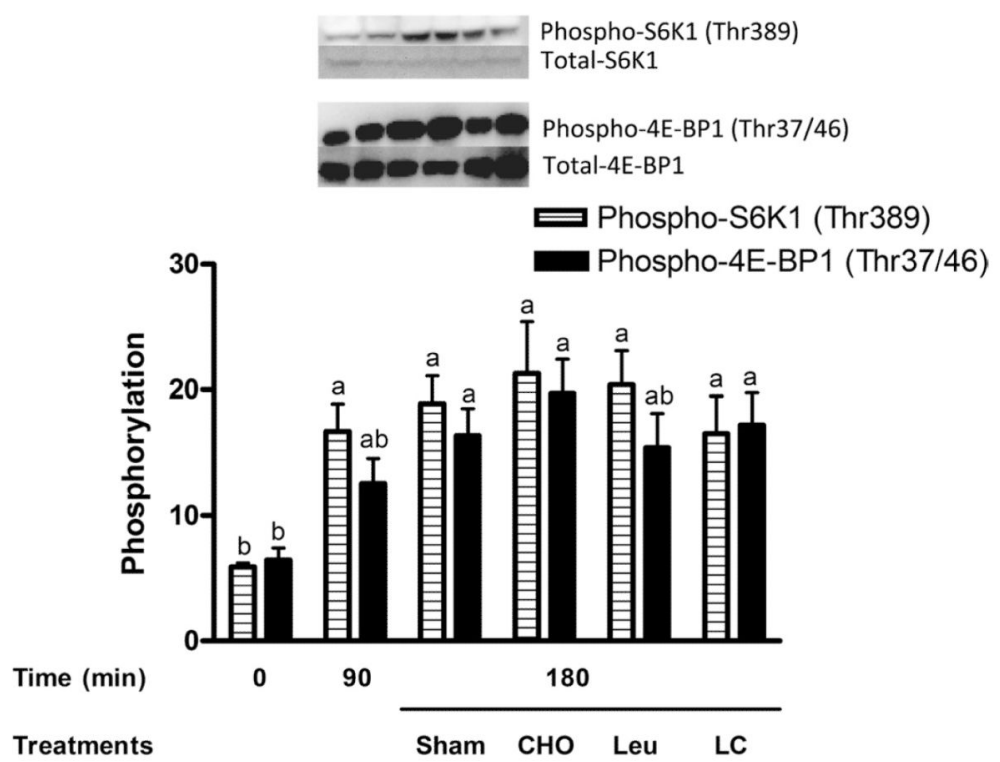

Fig. 4.

Postprandial changes in the relative phosphorylation state of ribosomal S6 protein kinase 1 [phospho-S6K1 ( Thr $^{389}$ )/total S6K1] and eukaryotic initiation factor-4E (eIF4E)-binding protein-1 [phospho-4E-BP1 $\left(\mathrm{Thr}^{37 / 46}\right) /$ total 4E-BP1]. Treatment groups were intubated at 135 min after the meal with water (sham), CHO, Leu, or LC. Data are means \pm SE; $n=4-6$. Means without a common letter differ $(P<0.05)$. 


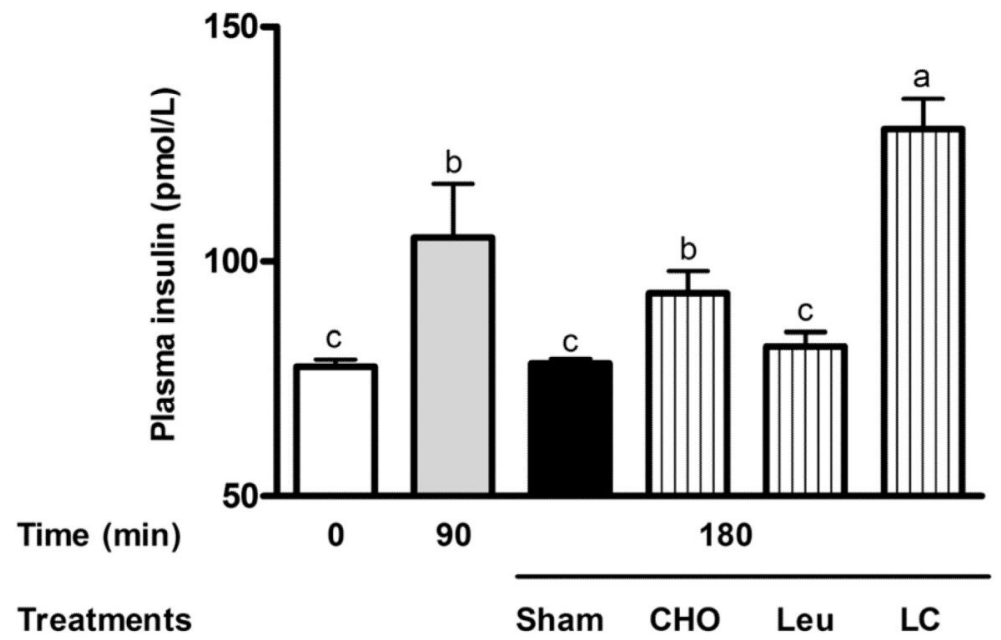

Fig. 5.

Postprandial changes in plasma insulin. Treatment groups were intubated at $135 \mathrm{~min}$ after the meal with water (sham), CHO, Leu, LC. Data are means \pm SE; $n=4-6$. Means without a common letter differ $(P<0.05)$. 


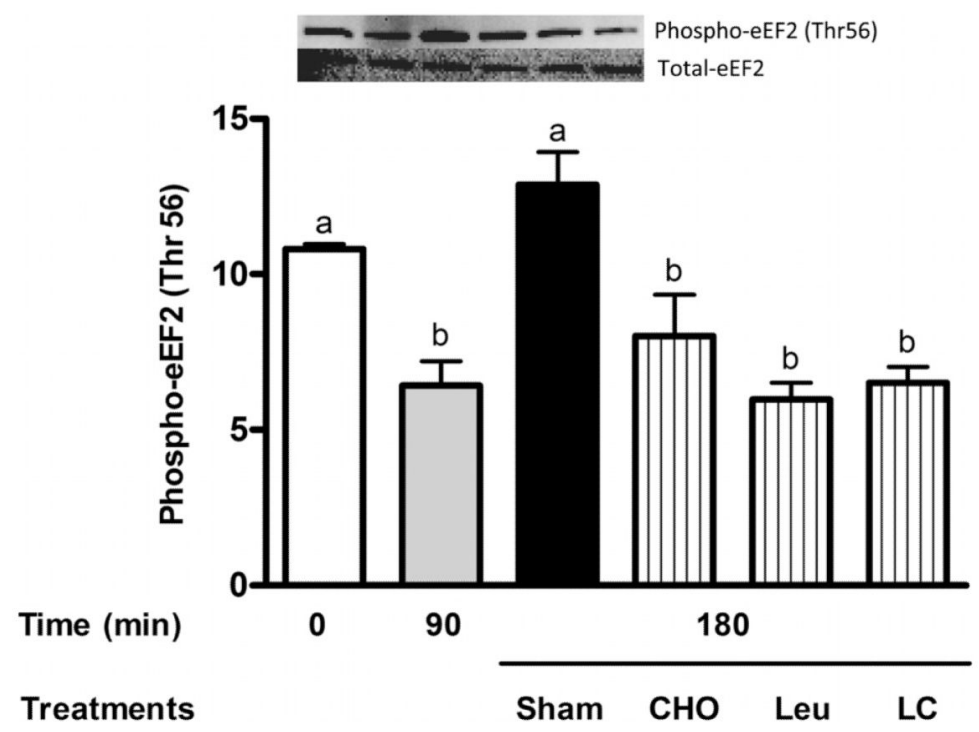

Fig. 6.

Postprandial changes in the relative phosphorylation state of eukaryotic elongation factor 2 [phospho-eEF2 $\left(\mathrm{Thr}^{56}\right) /$ total eEF2]. Treatment groups were intubated at $135 \mathrm{~min}$ after the meal with water (sham), CHO, Leu, or LC. Data are means \pm SE; $n=4-6$. Means without a common letter differ $(P<0.05)$. 


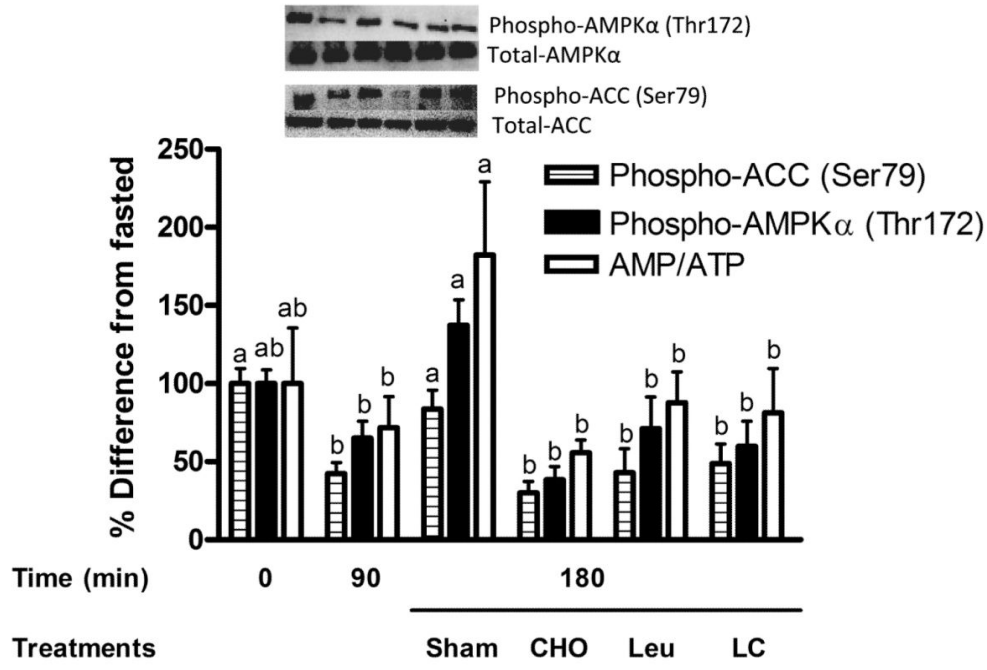

Fig. 7.

Postprandial changes in the relative phosphorylation states of adenosine monophosphateactivated protein kinase-a [phospho-AMPKa $\left(\mathrm{Thr}^{172}\right) /$ total AMPKa] and acetyl-CoA carboxylase [phospho-ACC $\left(\mathrm{Ser}^{79}\right) /$ total ACC] and nucleotide ratio of AMP/ATP (adenosine 5'-monophosphate/adenosine 5'-triphosphate). Treatment groups were intubated at 135 min after the meal with water (sham), CHO, Leu, or LC. Data are expressed as $\%$ change from fasted (time 0 ) values. Data are means \pm SE; $n=4-6$. Means without a common letter differ $(P<0.05)$. 


\section{Table 1}

\section{Meal composition}

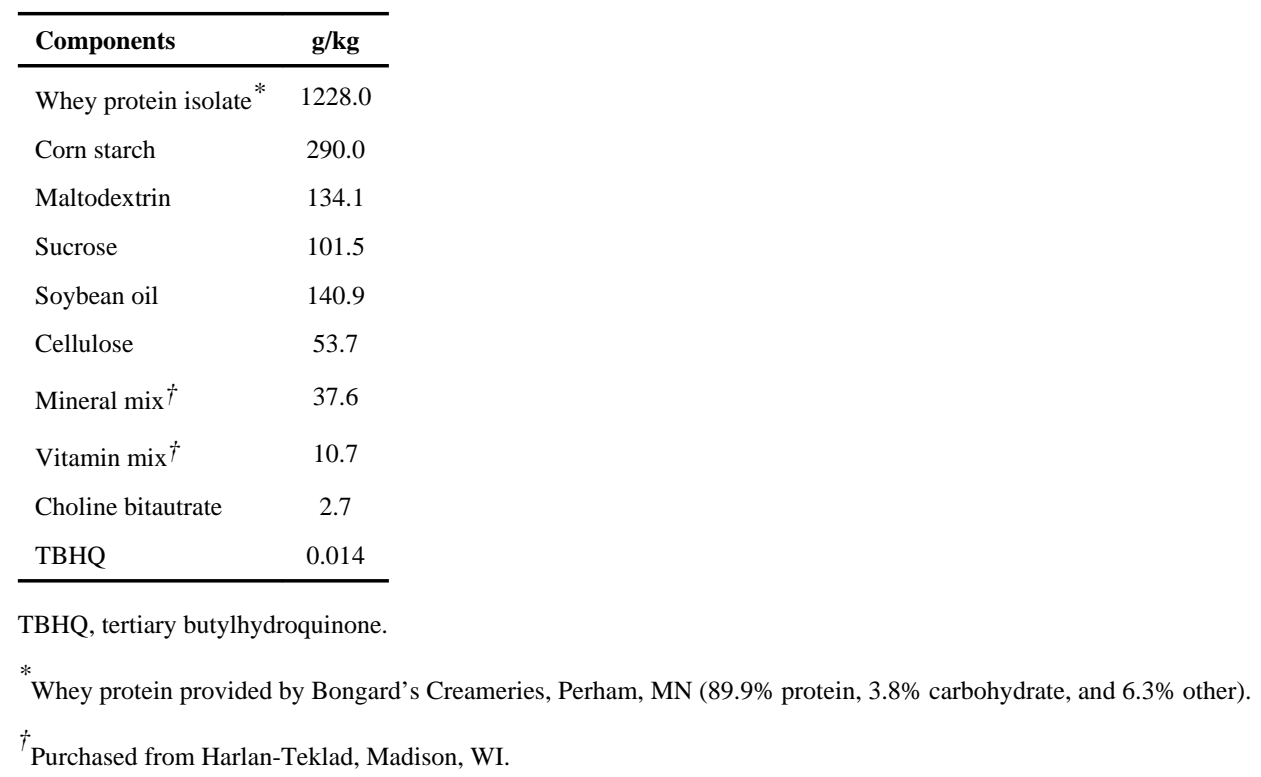




\section{Table 2}

Postprandial concentrations of selected essential amino acids in plasma following meal consumption

\begin{tabular}{lccc}
\hline Time, min & $\mathbf{0}^{*}$ & $\mathbf{9 0}$ & $\mathbf{1 8 0}$ \\
\hline Leucine & $200 \pm 18^{\mathrm{b}}$ & $297 \pm 31^{\mathrm{a}}$ & $312 \pm 19^{\mathrm{a}}$ \\
Isoleucine & $100 \pm 11^{\mathrm{b}}$ & $150 \pm 16^{\mathrm{a}}$ & $148 \pm 12^{\mathrm{a}}$ \\
Valine & $171 \pm 19^{\mathrm{a}}$ & $221 \pm 25^{\mathrm{a}}$ & $243 \pm 13^{\mathrm{a}}$ \\
Lysine & $569 \pm 33^{\mathrm{b}}$ & $724 \pm 61^{\mathrm{a}}$ & $595 \pm 38^{\mathrm{a}, \mathrm{b}}$ \\
Methionine & $72 \pm 8^{\mathrm{a}}$ & $88 \pm 6^{\mathrm{a}}$ & $88 \pm 5^{\mathrm{a}}$ \\
Threonine & $799 \pm 96^{\mathrm{a}}$ & $982 \pm 71^{\mathrm{a}}$ & $993 \pm 68^{\mathrm{a}}$ \\
\hline
\end{tabular}

Values are expressed as means $\pm \mathrm{SE}$ and in $\mu \mathrm{mol} / 1 ; n=4-6$. Means without a common letter differ $(P<0.05)$.

Twelve-hour food-deprived controls. 